\title{
Note: A balloon-borne accelerometer technique for measuring atmospheric turbulence
}

Article

Accepted Version

Marlton, G. J., Giles Harrison, R., Nicoll, K. A. and Williams, P.

D. (2015) Note: A balloon-borne accelerometer technique for measuring atmospheric turbulence. Review of Scientific Instruments, 86 (1). 016109. ISSN 0034-6748 doi:

https://doi.org/10.1063/1.4905529 Available at https://centaur.reading.ac.uk/39667/

It is advisable to refer to the publisher's version if you intend to cite from the work. See Guidance on citing.

To link to this article DOI: http://dx.doi.org/10.1063/1.4905529

Publisher: AIP

All outputs in CentAUR are protected by Intellectual Property Rights law, including copyright law. Copyright and IPR is retained by the creators or other copyright holders. Terms and conditions for use of this material are defined in the End User Agreement.

www.reading.ac.uk/centaur 
Central Archive at the University of Reading

Reading's research outputs online 


\title{
A balloon-borne accelerometer technique for measuring atmospheric turbulence
}

\author{
Graeme J. Marlton ${ }^{1, *}$, R. Giles Harrison ${ }^{1}$, Keri A. Nicoll ${ }^{1}$, Paul D. Williams ${ }^{1}$ \\ ${ }^{1}$ Department of Meteorology, University of Reading, Earley Gate, Reading RG6 6BB, United Kingdom
}

\begin{abstract}
A weather balloon and its suspended instrument package behave like a pendulum with a moving pivot. This dynamical system is exploited here for the detection of atmospheric turbulence. By adding an accelerometer to the instrument package, the size of the swings induced by atmospheric turbulence can be measured. In test flights, strong turbulence has induced accelerations greater than $5 g$, where $g=9.81 \mathrm{~m} \mathrm{~s}^{-2}$. Calibration of the accelerometer data with a vertically orientated lidar has allowed eddy dissipation rate (EDR) values of between $10^{-3}$ and $10^{-2} \mathrm{~m}^{2} \mathrm{~s}^{-3}$ to be derived from the accelerometer data. The novel use of a whole weather balloon and its adapted instrument package can be used as a new instrument to make standardized in situ measurements of turbulence.
\end{abstract}

The atmosphere is constantly in turbulent motion. In addition to the homogeneous turbulence that is ubiquitous in fluids, the atmosphere also exhibits localized pockets of clear-air turbulence (CAT) in regions of large vertical wind shear. CAT can be hazardous to aircraft passengers, because it is invisible to both pilots and onboard instrumentation. CAT remains difficult to forecast, despite recent progress ${ }^{1,2}$, and it is predicted to intensify in response to climate change ${ }^{3}$, motivating the need for a deeper understanding of its sources and an improved predictive capability. Pilots report the intensity of turbulence to air traffic control. However, pilot reports (PIREPs) are subjective and qualitative measures that depend on the pilot's experience and the type of aircraft. More quantitative measurements of turbulence are possible using accelerometers, which are occasionally fitted to aircraft to calculate the eddy dissipation rate (EDR), an aircraftindependent meteorological measure of turbulence. The sampling of atmospheric turbulence by aircraft is inevitably biased, however, because planes will tend to avoid areas of suspected strong turbulence.

It therefore seems prudent to develop a standardized method of observing atmospheric turbulence without placing aircraft at risk. One method would be to use remote-sensing instruments such as mesospheric, stratospheric, and tropospheric (MST) wind profilers. However, these profilers have poor coverage and a substantial installation is required. Meteorological balloon soundings are launched multiple times daily and have an extensive global coverage, and they, like aircraft, experience turbulence but have no way of gauging it directly. The Thorpe method ${ }^{4}$ can identify turbulent length scales from radiosonde temperature profiles ${ }^{5,6,7,8}$, but this approach lacks a full experimental comparison with in situ measurements. Furthermore, radiosondes have previously been deployed to carry out in situ measurements of volcanic ash during a protective flight ban, ${ }^{9}$ demonstrating their use for making observations in conditions too dangerous for aircraft. A standard meteorological radiosonde measures pressure, temperature, relative humidity, and wind speed and direction. The addition of extra sensors maximizes information obtained from standard balloon flights.

This work describes a small accelerometer flown alongside a standard meteorological radiosonde and used to sense the motion of the radiosonde, from which a quantitative measure of turbulence can be derived. The radiosonde and instrument package can be represented as a pendulum with a moving pivot. The swing of the package is related to the

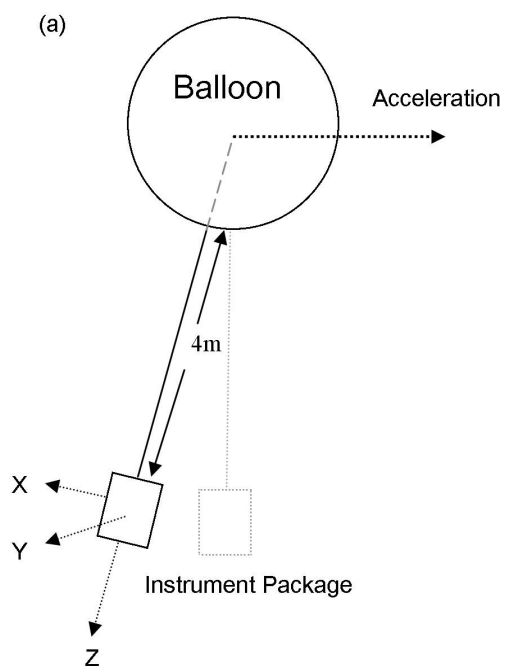

(b)

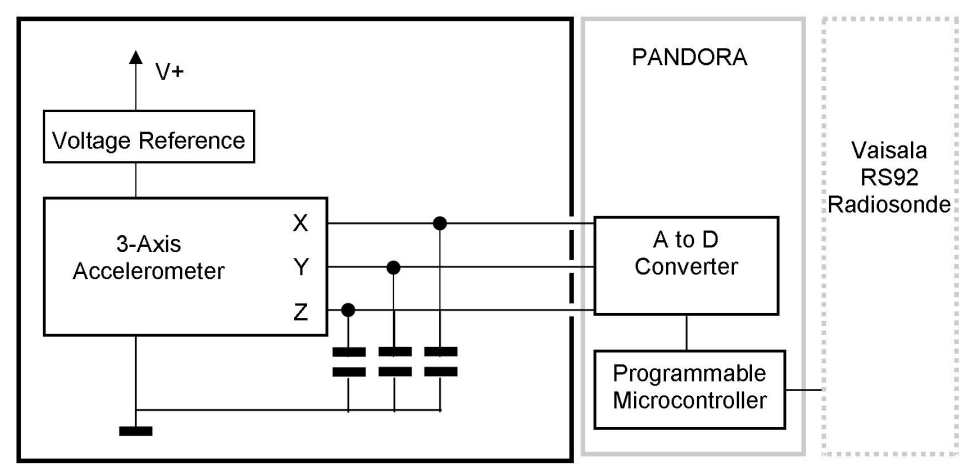

Figure 1: (a) The radiosonde instrument package is suspended $4 \mathrm{~m}$ beneath a helium-filled balloon. The acceleration of the balloon causes the instrument package to swing like a pendulum with a moving pivot. X, Y and $Z$ show the orientation of the accelerometer package. (b) The configuration of the accelerometer: measurements are obtained by the PANDORA data acquisition system and are transferred to the commercially available Vaisala $\mathrm{RS} 92$ radiosonde. 


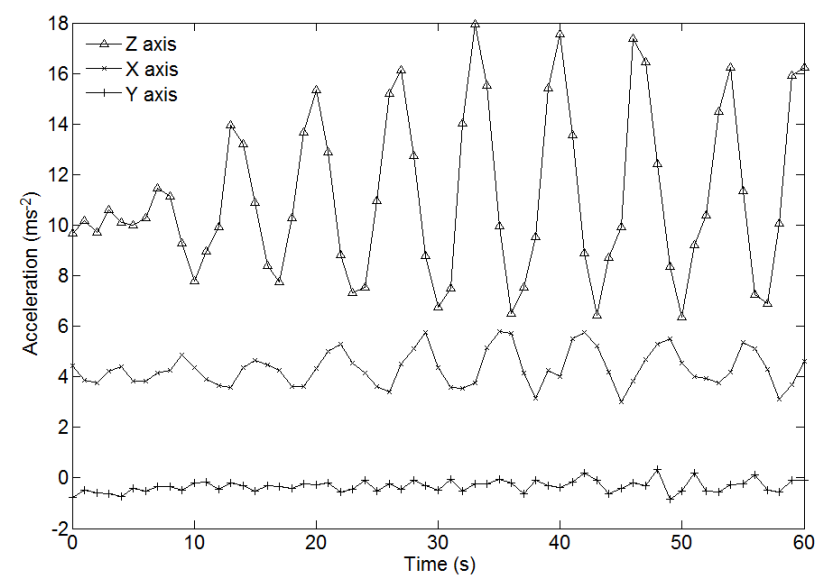

Figure 2: Results from swing tests on a prototype accelerometer package suspended from a mast, showing the z-axis sensor to have the greatest sensitivity to swinging motion. Offsets between each axis of the accelerometer are due to its orientation with respect to gravity

velocity change exerted by the wind on the balloon (Figure 1(a)).

A previous motion-sensing method for radiosondes used a magnetometer ${ }^{10,11}$. Here, an accelerometer is used instead, as it measures the motion of the swing in standard units of acceleration. Its excellent temperature stability is better suited to the extreme temperatures experienced on balloon flights and its low power consumption places less power demand on the radiosonde's battery. The package uses an ADXL325 accelerometer, which has three orthogonal measurement axes each with a minimal dynamic range of $\pm 5 g$, where $g$ is the acceleration due to gravity $\left(9.81 \mathrm{~m} \mathrm{~s}^{-2}\right)$. Internally, the accelerometer consists of a small microstructure mass supported by springs. Movement of the mass due to acceleration unbalances a differential capacitor, formed by a set of metal plates, producing a signal that is related to the movement of the mass. Post-processing by the accelerometer chip allows the direction and magnitude of the accelerations to be derived. ${ }^{12}$ The accelerometer is powered from a $3 \mathrm{~V}$ supply and presents separate analogue voltage signals for each axis. A $0.1 \mu \mathrm{F}$ capacitor is placed between each output and ground, to implement noise reduction as shown in Figure 1(b). The accelerometer data are transferred to a Vaisala RS92 radiosonde via the interface provided by a Programmable Analogue and Digital Operational Radiosonde Accessory (PANDORA) ${ }^{13}$.

A $5 g$ accelerometer device was chosen to provide sufficient range to measure the accelerations experienced by the package due to velocity changes in the balloon, yet resolve smaller motions of the balloon with a sensitivity of $14 \mathrm{mV}$ $\left(\mathrm{m} \mathrm{s}^{-2}\right)^{-1}$. The accelerometer detects the static acceleration due to gravity, enabling each axis of the accelerometer to be calibrated by rotating it about each axis before use. The results of ground tests, in which the instrument package was suspended from a mast, are shown in Figure 2. Prototype flights showed that the $z$-axis accelerometer had the best response to swinging induced by atmospheric motions on the balloon. Aseries of flights has been made from the Reading University Atmospheric Observatory (RUAO), $\mathrm{UK}$, at $51.4^{\circ} \mathrm{N}, 0.94^{\circ} \mathrm{E}$, starting in October 2013. Regions of turbulence that generate vertical accelerations of up to 60 $\mathrm{m} \mathrm{s}^{-2}$ on the sensor package have been observed on multiple occasions. Figure 3 shows a balloon flight in which incloud turbulence is detected at 2-6 km and CAT at 8-10 km (Figure 3c). CAT is present due to high wind shears in the jet stream region, apparent in the wind speeds (Figure $3 b$ ).
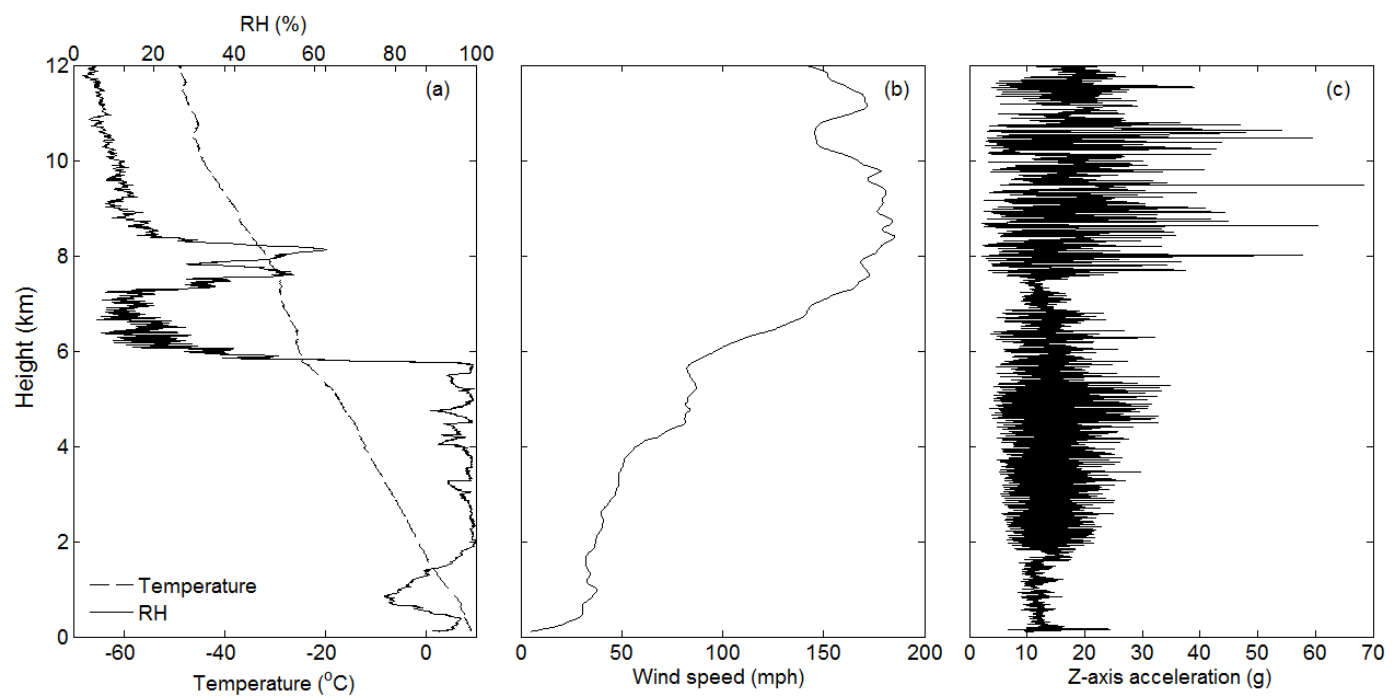

Figure 3 Vertical profiles from a balloon flight over Reading, UK, showing (a) temperature (dashed) and relative humidity (solid); (b) horizontal wind speed; and (c) acceleration detected by the z-axis of the accelerometer. These data were obtained on 5 November 2013. 


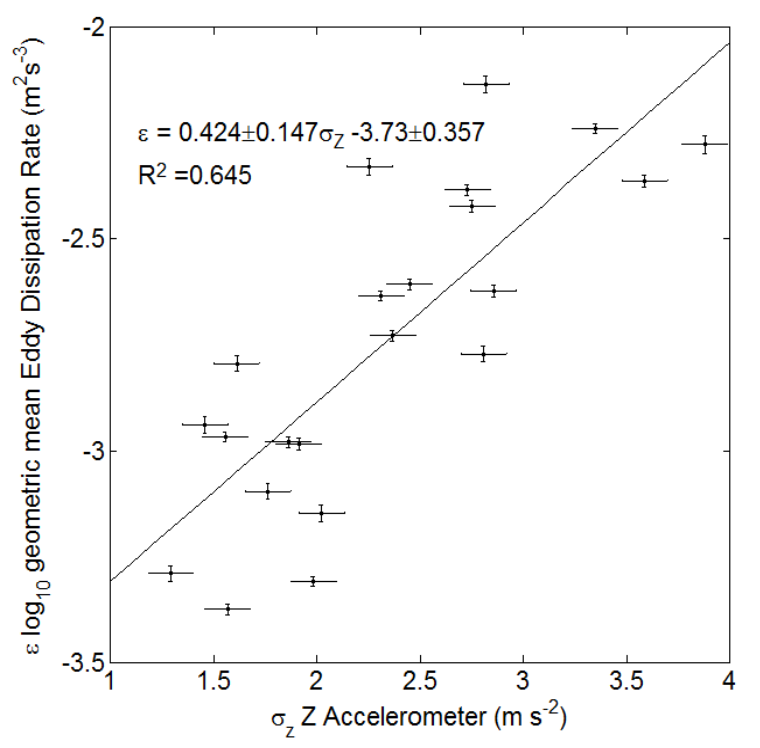

Figure 4:The logarithm (to base 10) of lidar-derived geometric-mean eddy dissipation rate $(E D R)$ in $m^{2} s^{-3}$ plotted against the standard deviation of the vertical accelerations within a $210 \mathrm{~m}$ height window from 13 flights through the boundary layer from RUAO.

A co-located Halo Photonics pulsed Doppler lidar was used to evaluate the accelerometer's response to turbulence. Using the lidar's vertical wind profile ${ }^{14}$ at a frequency of 1 $\mathrm{Hz}$, the eddy dissipation rate (EDR) - a meteorological measure of turbulence - may be calculated from the vertical wind velocity variance over a sampling period of $60 \mathrm{~s}$, by applying a length scale derived from the lidar's Doppler Beam Swinging profiling method ${ }^{15}$. The lidar's operating height range of $3 \mathrm{~km}$ limits its application to the lowest atmospheric regions, so EDR was calculated for the time of launch. Due to the nature of the radiosondes' random trajectories and the different sampling rates of the lidar, the lidar-derived values were averaged in time and space. Profiles were obtained 15 min either side of the launch time with a vertical height averaging window of $210 \mathrm{~m}$, due to the lidar's $30 \mathrm{~m}$ vertical resolution. Due to the logarithmic nature of the EDR values, a geometric mean was taken. Measures of the strength of the return beam were made using the signal-to-noise ratio and backscatter coefficient. They were used to remove spurious values, such as when lidar profiles inadvertently sampled a cloud base. The accelerometer used the same sample depth of $210 \mathrm{~m}$ for calculating the standard deviation of $z$-axis accelerometer, $\sigma_{\mathrm{z}}$. Points were removed with large uncertainties and those with unrealistic velocity spectra ${ }^{14}$. Figure 4 demonstrates the empirical relationship between $\sigma_{\mathrm{z}}$ and the lidar-derived EDR for 13 flights. Without theoretical expectations for the relationship expected, the lowest order statistical model of a linear fit is used; the $\mathrm{R}^{2}$ value of 0.645 obtained indicates its validity. The scatter is due to the lack of co-location between the sonde and the lidar measurements.
In summary, this work demonstrates the measurement of atmospheric turbulence using the dynamical system that is a weather balloon and a standard meteorological radiosonde with an accelerometer interfaced. Turbulence measured by the accelerometer using the empirical relationship can be reported as an eddy dissipation rate, allowing adapted radiosondes to make measurements of turbulence.

As mentioned earlier, the Thorpe analysis method also has the potential to derive turbulence information from ascent data. However, a substantial comparison with in-situ measurements is still needed to evaluate the method. Furthermore, the Thorpe method will require the effects of solar radiation, balloon wakes, and errors in temperature sensors to be considered. These effects are a function of the configuration of the balloon with regard to balloon size, tether length, and radiosonde type. In our current implementation, the balloon and instrumentation package are $4 \mathrm{~m}$ apart. As different meteorological organizations use different balloon sizes and string lengths ${ }^{17}$, future work will examine other configurations.

Acknowledgements. The radiosonde packages were funded by the Royal Society (grant number RG100661). GJM is funded by a NERC funded PhD studentship. PDW is funded by a University Research Fellowship from the Royal Society (UF080256), and KAN by a NERC Knowledge Exchange Fellowship.

${ }^{1}$ J.A. Knox, D.W. McCann and P.D. Williams, J. Atmos. Sci., 65(10), 2008, pp 3292-3304, doi:10.1175/2008JAS2477.1

${ }^{2}$ D.W. McCann, J.A. Knox and P.D. Williams, Met. Apps., 19(1), 2012, pp 71-78, doi: 10.1002/met.260

${ }^{3}$ P.D. Williams and M.M. Joshi, 2013, Nature Climate Change, 3(7), 2013, pp 644-648, doi:10.1038/nclimate 1866

${ }^{4}$ S.A. Thorpe, Phil. Trans. Royal Society Lond. Series A, 1977, pp125-181. ${ }^{5}$ C.A. Clayson and L. Kantha, J. Atm. \&Ocn. Tech., 25, 2008, pp833-852, doi:http://dx.doi.org/10.1175/2007JTECHA992.1

${ }^{6}$ R. Wilson, H. Luce, F. Dalaudier and J.Lefere, J. Atm. \&Ocn. tech., 27, 2010, pp977-993, doi: 10.1175/ 2010JTECHA1357.1.

${ }^{7}$ R.Wilson, F. Dalaudier and H. Luce, Atm. Measurement Tech., 4, 2011 pp969-1000, doi:10.5194/amt-4-795-2011

${ }^{8}$ R. Wilson, H. Luce, H. Hashiguchi and M Shiotani, Atm. Measurement Tech., 6, 2013, pp697-702, doi: 10.5194/amt-6-697-2013

${ }^{9}$ R.G. Harrison, K.A. Nicoll, Z. Ulanowski\& T.A Mather, Env. Res. Letters,5(2), 2010, 024001, doi:10.1088/1748-9326/5/2/024004.

${ }^{10}$ R.G. Harrison and R.J Hogan, Notes and Correspondence, J. Atm. \&Ocn. Tech., Volume 24, 2006, pp 517

${ }^{11}$ R.G. Harrison, G.W. Rogers and R.J. Hogan, Rev. Sci.

Instruments,78(12), 2007, 124501, doi: 10.1063/1.2815349.

${ }^{12}$ Analog Devices, Small, low power, 3 -axis, $\pm 5 \mathrm{~g}$ Accelerometer, data sheet, 2009

${ }^{13}$ R.G. Harrison, K.A. Nicoll, A.G. Lomas, Rev. Sci. Instruments, 83(3), 2012, 036106,doi:10.1063/1.3697717.

${ }^{14}$ E.J O’Connor, A.J. Illingworth, I.M. Brooks, C. D. Westbrook, R.J. Hogan, F Davies and B.J. Brooks, J. Atm. \&Ocn. Tech., 27(10), 2010, pp1652, doi: 10.1175/2010MWR3482.1

${ }^{15}$ S.E. Lane, J.F. Barlow and C.R. Wood, 2013, J. Wind Eng. \& Ind. Aero., 119, 2013, pp 53, doi: http://dx.doi.org/10.1016/j.jweia.2013.05.010.

${ }^{16} \mathrm{R}$. Sharman, C. Tebaldi, G. Weiner and J.Wolff, Weather and

Forecasting, 21, 2006, pp 268, doi: http://dx.doi.org/10.1175/WAF924.1

${ }^{17}$ J. K. Luers\& R. E. Eskridge, J. Climate, 11, 1998, pp1002-1019 